\title{
Article \\ Effective Condensing Dehumidification in a Rotary-Spray Honey Dehydrator
}

\author{
Marcin Morawski ${ }^{1}\left(\mathbb{D}\right.$, Marcin Malec $^{1}$ and Beata Niezgoda-Żelasko ${ }^{2, *(1)}$ \\ 1 Department of Production Engineering, Cracow University of Technology, Al. Jana Pawła II 37, \\ 31-864 Krakow, Poland; marcin.morawski@pk.edu.pl (M.M.); marcin.malec@pk.edu.pl (M.M.) \\ 2 Department of Thermal and Process Engineering, Cracow University of Technology, Al. Jana Pawła II 37, \\ 31-864 Krakow, Poland \\ * Correspondence: bniezgo@mech.pk.edu.pl
}

Citation: Morawski, M.; Malec, M.; Niezgoda-Żelasko, B. Effective Condensing Dehumidification in a Rotary-Spray Honey Dehydrator. Energies 2022, 15, 100. https:// doi.org/10.3390/en15010100

Academic Editor: Mikhail Sheremet

Received: 11 November 2021

Accepted: 17 December 2021

Published: 23 December 2021

Publisher's Note: MDPI stays neutral with regard to jurisdictional claims in published maps and institutional affiliations.

Copyright: () 2021 by the authors Licensee MDPI, Basel, Switzerland. This article is an open access article distributed under the terms and conditions of the Creative Commons Attribution (CC BY) license (https:// creativecommons.org/licenses/by/ $4.0 /)$.

\begin{abstract}
This paper presents a mathematical model of the heat and mass transfer processes for a rotary-spray honey dehydrator with a heat pump and a closed air circuit. An analytical calculation model, based on the energy balance equations of the dehydrator and heat pump, was used to model the transient dehydration process of honey in a dehydrator. The presented article includes a different approach to modelling both the dryer and the heat pump assisting the drying process. The novel quality of this study lies in the use of original equations to determine the heat and mass transfer coefficients between honey and air and using an actual model of a cooling unit to model the honey dehydration process. The experimentally verified calculation algorithm enables an analysis of the effects of air flow rate, mixer rotation speed, and cooling unit power on the efficiency of the drying process. The dehydrator calculation model was used to minimize the drying time by selecting the optimal evaporative temperature values of the cooling unit. For fixed mixer speed and air flow rates, optimal values of evaporation temperatures allow for $8-13 \%$ reduction in honey drying time and an increase in the specific moisture extraction rate (SMER) by $4-32 \%$.
\end{abstract}

Keywords: rotary-spray honey dehydrator; modelling heat and mass transfer; optimal operating parameters

\section{Introduction}

According to [1], honey is a food product with an average water content of $16-18 \%$ and with total amount of sugars fructose and glucose below $70 \%$.

Commercial honey must not contain more than $20 \%$ water by weight. Honey that is too moist tends to ferment and is not suitable for storage. It is not always possible to obtain honey with adequate moisture content under natural conditions. The occurrence of abundant forage from plants such as rapeseed or goldenrod, rains and sudden weather changes result in more moisture content in the honey. Goldenrod honey tends to ferment even when its moisture content is slightly below $20 \%$. It is difficult to achieve the desired low moisture content when harvesting this type of honey, and as a result, almost every batch must be mechanically dried. An increasing number of beekeepers are struggling with the problem of drying the honey they produce and are looking for efficient, lowcost (in terms of both investment and operation) units to carry out this task. Honey dehydration is carried out in what are called honey dehydrators [2], which belong to the group of dehydrators used in the agricultural industry [3]. Honey is dried in medium or low-capacity dehydrators [4-10] as well as large industrial installations [11].

Drying honey in dehydrators usually follows a procedure similar to that implemented in direct and indirect evaporative coolers and involves the evaporation of water from the honey into dehumidified air. The honey-drying process uses the difference in partial pressure of the moisture contained in honey and the water vapour in the drying air. The process is most often associated with raising the temperature of the honey and evaporation 
of the moisture contained in the honey into the air under atmospheric pressure conditions. The heat sources for honey include: drying air $[4,6,10]$, outside air [7], or an additional external heat source [6-8]. Some solutions use heating water circulating in a water jacket of the honey tank to heat the honey. As a rule, a honey dehydrator includes three basic systems. These systems are a honey circuit, an air circuit, and a system for maximising the honey-air contact area. Increasing the honey-air contact area is achieved with honeysupplied spray systems [6,10], falling film heat exchangers [11], various types of honey mixers with air jets $[4,5]$. The air used to dry the honey may be atmospheric air or air circulating in a closed system between the honey tank and the drying unit.

Compressed atmospheric air supplied to honey tanks can be used for rinsing, mixing, and drying honey [7]. Devices are available that utilise the natural evaporation of water from honey into the ambient air [8]. In this case, heated honey is pumped onto a large open, flat surface on which the evaporation process takes place. The mass exchange process in honey dehydrators is intensified by increasing the flow rate of atmospheric air pumped through with fans $[4,7,8,10]$ and lowering the relative humidity of the air with a simultaneous increase in its temperature. Air drying can be implemented by cooling [6] or adsorption drying [9]. Various adsorbents with different adsorption capacity such as silica gels, zeolites, composites, activated carbon, metal organic frameworks, or even dry coconut coir and durian peels can be used for air dehumidification [12]. In industrial dehydrators, however, water evaporation is carried out with the use of vacuum $[11,13,14]$. Vacuum drying involves the evaporation of water under low pressure conditions where the boiling temperature of the water inside the substance dried product is approx. $25-30{ }^{\circ} \mathrm{C}$. This intensifies the process of water evaporation into the drying air. This type of honey dehumidification is particularly desired for its speed and preserving the enzymes activity in honey due to low-temperature treatment [13]. There are also hybrid solutions, such as vacuum freeze drying $[14,15]$ in which water removal from honey is carried out by sublimation of ice from the dried substance under low pressure (below 611.2 Pa) and temperature (e.g., in the range $-40 ;-25^{\circ} \mathrm{C}$ ).

In paper [16], the authors described the effect of ultrasound processing as well as microwave heat processing of honey on moisture content in the product. Short (60 s) microwave heating of honey with power of 400-800 W allows to obtain the moisture content of $19.8 \%$. Ultrasound processing of honey for 3-4 min also allows to obtain commercially acceptable moisture content in honey.

The information available in the literature on honey dehydrators is, for the most part, limited only to a discussion of dehydrator design and determination of the change in honey moisture content over time and dehydrator energy consumption. A more extensive analysis of the effect of honey temperature $\left(21-38^{\circ} \mathrm{C}\right)$ and drying air temperature $\left(8-40^{\circ} \mathrm{C}\right)$ on honey drying time was presented in [10]. Gill et al. [10] indicated that higher honey and air temperatures are conducive to obtaining shorter drying times and reduced energy consumption. In [14], the authors analysed the effects of vacuum drying and freeze drying as well as honey cooling temperatures on the drying time of sunflower and acacia honey. Experimental results indicated that regardless of the type of honey, freeze drying and the use of low product freezing temperatures (e.g., $-40^{\circ} \mathrm{C}$ ) result in better drying efficiency. The study [17] is the first paper to present a theoretical and experimental analysis of heat and mass transfer processes in a rotary-spray honey dehydrator with closed-circuit airflow and heat pump support. Based on their experimental results, the authors [17] proposed criterion relationships for calculating heat and mass transfer coefficients between honey and air for a vertical honey dehydrator equipped with a spraying system, honey mixers, and an air drying and heating system with an external heat pump.

Issues related to the modelling of stable heat and mass transfer processes between water and air during evaporative cooling were considered in articles [18-22]. The issues of modelling the processes of heat and mass exchange in the dryers used in the agricultural industry are discussed, among others, in articles [23-28]. Using differential equations of diffusion and heat transfer in the dried material (leather), assuming constant heat and mass 
transfer conditions between the air and the dried material, Haghi [23] analysed the change in humidity and temperature of the dried material as a function of time, inside and on its surface. A complex calculation model of a heat pump dehumidifier is presented in the articles $[24,25]$. The dryer model includes the energy balance equations for a thin bed of alfalfa, the thin-layer drying equation, along with the drying constant and equilibrium moisture content specific to alfalfa. The dryer model was complemented by a heat pump model containing Peclet balance equations for the evaporator and condenser. The authors neglected the effect of the specifications of the compressor and expansion element on the performance of the heat pump. The study [26] describes the selection process of air mass flow rate, air temperature, recycle air ratio, and evaporator bypass air ratio in the context of reducing the drying costs for papaya and mango fruit. The drying chamber model included the energy and mass balance between air and fruit. The change in fruit moisture content was calculated from the drying kinetics equation using the drying constant and equilibrium moisture content typical for the mango and papaya fruit. The model of the heat exchangers of the heat pump included the general equations of energy balance between the refrigerant and the drying air. To determine the energy consumption of the compressor, Therkeld's equation for a reciprocating compressor was used [26]. In the paper by Louarn, et al. [27] modelling of the drying process of a three-centimetre layer of manure is presented. Having solved the equations of conservation of mass and energy and taking into account the phenomena of evaporation, liquid and vapour diffusion, the influence of various drying conditions (warm air stream convective drying, drying a heated sample with an atmospheric air, combined drying) on the amount of water and surface temperature of the dried product was analysed. Simulation and experimental results showed the highest drying kinetics for combined drying.

Selected issues of modelling mass exchange processes in honey dehydrators are included in the paper [14]. Using the drying kinetics equation and experimental results for drying honey by vacuum and freeze-drying methods, the authors determined the effective moisture diffusivity coefficient for honey. For the honey types tested and the experimental drying temperatures $\left(-40{ }^{\circ} \mathrm{C},-20{ }^{\circ} \mathrm{C},+25^{\circ} \mathrm{C}\right)$ Nedić et al. [14] proposed equations to approximate experimental results, allowing us to determine the change in moisture content in honey as a function of time.

The authors use different numerical methods depending on the complexity of the physical phenomena, the geometry of the problem, and the purpose of the calculations. A modern approach to modelling and solving the governing equations for complex heat and momentum transfer problems is to use the finite element or finite volume methods, with various procedures for solving these equations [29-31]. Especially complex multiphase flow problems with varying fluid physical properties and varying boundary and initial conditions are solved using numerical tools such as Ansys or OpenFOAM. Simpler problems describing interaction of several devices can be solved using computational procedures supplemented with software libraries (IMSL Fortran Numerical Library) including, for example, solving systems of partial differential equations and solving optimisation problems [21]. In the case of one-dimensional problems, mathematical modelling of the process can be reduced to step-by-step solving of successive equations describing the course of the process or the operation of the system of devices in macroscopic scale [28].

A literature review indicates that in the case of honey dehydrators [2-16], there is a lack of studies concerning the modelling of heat and mass transfer processes in these devices. In this case, the authors focus on presentation, comparison of different dehydration technologies in the context of drying time, obtained honey moisture content, and energy consumption. Studies [23-28] discussing the issues of modelling drying processes are concerned with modelling the drying of biosolids and the use of vapour-liquid diffusion equations in solids in mass exchange modelling. Complex general mathematical models of cooling units (compressors, heat exchangers) used in these papers may cause discrepancies between the model and the real object. 
To the authors' knowledge, the presented paper is the first publication on the numerical modelling of a transient, non-adiabatic honey dehydration process in a vertical centrifugal honey dehydrator with an external electric heat source and a closed air circuit and heat pump. The scientific objective of the presented article was to propose a different approach to modelling both the dryer and the heat pump assisting the drying process. The new issues discussed in the article are the heat balance equations of the dehydrator tank and the heat and mass transfer process between honey and air. For modelling the heat and mass transfer processes, the authors used their original equations to determine the heat and mass transfer coefficients between honey and air. The actual operating characteristics of the cooling unit were used to model the heat transfer process in the unit. The latent heat flux in the evaporator was determined based on the value of the degree of process openness $(R C J)$. The experimentally verified thermal calculation model was used to analyse the effect of air flow rate, mixer speed, and evaporation temperature of the cooling unit on the efficiency of the honey drying process. The mutual effect of the operating parameters of the dehydrator and cooling unit on honey drying process time was quantified for the drying process for the very first time. The ultimate objective of this article is focused on a solution to the problem of determining the optimal value of the evaporation temperature of the cooling unit in the context of reducing the duration of the honey dehydration process and maximization of the specific moisture extraction rate.

\section{Materials and Methods}

\subsection{Heat and Mass Exchange in a Honey Dehydrator}

The subject under consideration is a vertical rotary-spray (centrifugal) honey dehydrator (Figure 1) [32] in which direct contact between warm dry air stream and heated honey is achieved by means of a special spraying unit (1) and a mixer (2). The dehydrator is formed by two major systems: the honey drying system and the air drying system. The fan forces air flow through honey tank and the dryer. A commercial cooling unit-a heat pump-is used to dry the air (3). The air is cooled and dried in the evaporator of the heat pump (4) and reheated in the condenser of the cooling unit (5).

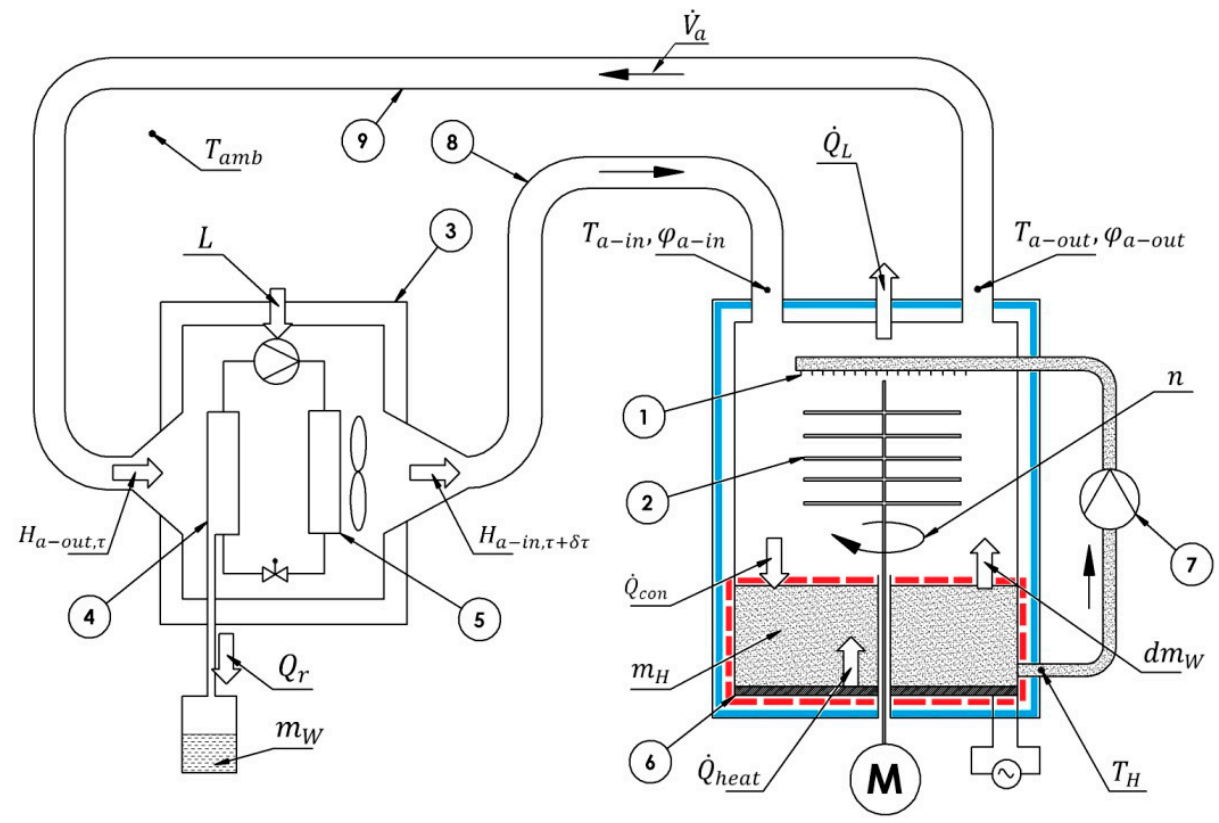

Figure 1. Schematic diagram of a closed-loop honey dehydrator: 1-honey sprayer; 2 -mixer; 3-heat pump; 4-evaporator; 5-condenser; 6-electric heaters; 7-honey pump system; 8-air supply line; 9-air return line.

The contact between air and honey occurs in a vertical, thermally insulated tank equipped with a specially designed mixer (2) driven by a DC motor. The role of the mixer 
is to increase the area of contact between air and honey. Surface electric resistance heaters (6) with adjustable power are located at the bottom of the tank. The honey pumping system (7) is used to transfer honey from the bottom of the tank to the sprayer mounted above the mixer. Flexible air hoses (8) and (9) are used to provide air flow between the tank and the heat pump.

A detailed description of the heat and mass transfer processes and experimental results of a closed-loop honey dehydrator were described in the article [17].

Experimental research indicated that:

- The heat and mass transfer processes under consideration are transient;

- In the initial phase, the heaters and air transfer heat to the honey changing its temperature-the heating phase;

- Once the temperature difference between the inlet air and the honey has stabilised, the dominant process occurring between the honey and air is the mass exchange process-the drying phase.

- The stabilisation of the mass flux of evaporating water is accompanied by the maximisation of the heat flux transferred by air to honey by convection and maximisation of the values of heat transfer coefficients;

- Low mixer speeds corresponded to the maximum values of heat transfer and mass transfer coefficients;

- Higher air flow velocities and higher heat flux densities are conducive to higher values of heat transfer coefficients;

- In the case of mass transfer coefficients, a clear effect of the actual honey-air contact area (mixer speed) on the intensity of the mass exchange process was observed. The effect of air velocity on the mass transfer rate was significant until a certain limit of air velocity was reached due to the limited drying capability of the external cooling unit. - With the increase in the driving force of the mass transfer process $\left(\Delta X=X^{\prime \prime}\left(T_{H}, A_{w}\right)\right.$ $\left.X\left(T_{a-i n}, \varphi_{a-i n}\right)\right)$, a slight decrease in mass transfer coefficients was observed.

The experimental results presented in [17] were generalised through criterion equations to determine the values of heat (1) and mass transfer (2) coefficients in geometrically similar honey dehydrators:

$$
\begin{gathered}
N u=\frac{\alpha \cdot d_{h}}{\lambda_{a}}=B_{1} \cdot \operatorname{Re}_{a}^{B_{2}} \cdot \operatorname{Re}_{H}^{B_{3}} \cdot K^{B_{4}} \operatorname{Pr}_{a}^{0.33}, \\
S h=\frac{\beta \cdot d_{h}}{D_{a} \cdot \rho_{a}}=C_{1} \cdot R e_{a}^{C_{2}} \cdot R e_{H}^{C_{3}} \cdot S c_{a}^{C_{4}}
\end{gathered}
$$

The values of the $B_{\mathrm{i}}$ and $C_{\mathrm{i}}$ coefficients in Formulas (1) and (2) are summarised in Table 1. The scope of validity of Formulas (1) and (2) included the following ranges of variation of the criterion numbers: $600 \leq R e_{p} \leq 2400,2400 \leq R e_{H} \leq 11,000,0.13 \leq K \leq 0.4$, $1.8 \leq S c \leq 5.8$.

\begin{tabular}{|c|c|c|c|c|c|c|}
\hline \multirow{3}{*}{$N u(1)$} & \multicolumn{2}{|c|}{$B_{1}$} & \multirow[t]{2}{*}{$B_{2}$} & \multirow[t]{2}{*}{$B_{3}$} & \multicolumn{2}{|c|}{$B_{4}$} \\
\hline & transient & $\begin{array}{l}\text { steady } \\
\text { state }\end{array}$ & & & transient & $\begin{array}{c}\text { steady } \\
\text { state }\end{array}$ \\
\hline & 140.8 & 601.9 & 0.4203 & -0.4718 & -0.6313 & 0 \\
\hline \multirow{3}{*}{ Sh (2) } & \multicolumn{2}{|c|}{$C_{1}$} & $C_{2}$ & $C_{3}$ & \multicolumn{2}{|c|}{$C_{4}$} \\
\hline & transient & $\begin{array}{l}\text { steady } \\
\text { state }\end{array}$ & & & transient & $\begin{array}{c}\text { steady } \\
\text { state }\end{array}$ \\
\hline & 0.8479 & 1.299 & 0.9728 & -0.4072 & 0.3713 & 0 \\
\hline
\end{tabular}

Table 1. Values of the Bi and Ci coefficients in Equations (1) and (2) [17]. 
In paper [17], at each time step, the measured inlet and outlet parameters of air, honey, and water received in the dehydrator were used to determine criterion equations of the form (1) and (2). In the study presented here, the initial honey and air parameters and the heat and mass balance equations of the dehydrator, supplemented by the criterion Equations (1) and (2) and the heat balance equations of the cooling unit, were used to determine the air and honey parameters at successive time steps in the honey dehydration process.

\subsection{Mathematical Model of the Heat and Mass Transfer Process for the Dehydrator}

A mathematical model of a closed-loop honey dehydrator was derived from the heat and mass balance for the main modules of the dehydrator: the honey tank and the cooling unit. The heat and mass transfer balance of the honey dehydrator was prepared with the following assumptions:

- $\quad$ The process is transient;

- The dry air mass flux is constant;

- The ambient temperature is constant;

- At the time $\tau$, the output parameters of the air from the dehydrator tank are the input parameters for the cooling unit;

- At the time $\tau$, the output parameters of the air from the cooling device are the input parameters for the dehydrator tank at the time $\tau+\delta \tau$;

- The effect of honey pump operation on the heat balance of the dehydrator tank is ignored;

- The heat exchange process of the heat pump with the environment is omitted.

The heat balance for the dehydrator in transient conditions prepared for the balance shield marked in red in Figure 1 is presented in Equation (3).

$$
\dot{Q}_{\text {con }} \cdot \delta \tau+\dot{Q}_{\text {heat }} \cdot \delta \tau=\delta m_{H} \cdot h^{\prime \prime}\left(T_{\tau+\delta \tau}\right)+\delta Q_{H}+\dot{Q}_{L}^{*} \cdot \delta \tau \text {, }
$$

In the time $\delta \tau$, the heat applied to the honey causes the evaporation of water in the amount of $\delta m_{H}$ whose temperature changes from the initial value $T_{\tau}$ to the value of $T_{\tau+\delta \tau}$, and whose specific enthalpy corresponds to the enthalpy of water vapour $h^{\prime \prime}=r+c p^{\prime \prime} \cdot T_{\tau+\delta \tau}$. The change in honey weight and the change in temperature are related to the change in the heat accumulated in honey $\delta Q_{H}$. The heat sources in the dehydrator tank are air, which exchanges heat with honey by convection $\left(\dot{Q}_{c o n} \cdot \delta \tau\right)$, and electric heaters $\left(\dot{Q}_{\text {heat }} \cdot \delta \tau\right)$. Some of the heat supplied by the heaters and air is transferred, due to heat loss, to the environment $\left(\dot{Q}_{L}^{*} \cdot \delta \tau=U \cdot A_{T}^{*} \cdot\left(T_{\tau}-T_{a m b}\right) \cdot \delta \tau\right)$. In this case, the value of heat loss to the environment is determined by the Peclet relationship in which the surface area of the heat transfer $\left(A_{T}^{*}\right)$ corresponds to the surface area of the part of the tank filled with honey.

The heat accumulated in honey in the time $\delta \tau$ can be determined from relationship (4):

$$
\delta Q_{H}=\left(m_{H}-\delta m_{H}\right) \cdot c p_{H}\left(X_{\tau+\delta \tau}\right) \cdot T_{\tau+\delta \tau}-m_{H} \cdot c p_{H}\left(X_{\tau}\right) \cdot T_{\tau}
$$

The heat flux exchanged between air and honey by convection can be determined from Newton's Equation (5), in which the heat transfer coefficient is determined from Equation (1):

$$
\dot{Q}_{\text {con }}=\alpha \cdot A \cdot\left(T_{a-i n, \tau}-T_{\tau}\right)
$$

The amount of water evaporating into the air is determined by Equation (6), in which the mass transfer coefficient is calculated from Equation (2).

$$
\delta m_{H}=\beta \cdot A \cdot\left(X_{a}^{\prime \prime}\left(T_{\tau}, A_{w}\right)-X_{a}\left(T_{a-i n, \tau}, \varphi_{a-i n, \tau}\right)\right) \cdot \delta \tau
$$

Water activity $A_{w}$ for multifloral honey can be calculated from relationship (7) [33]:

$$
A_{w}=0.19964+0.020579 \cdot\left(100 \cdot X_{\tau}\right)
$$


Air humidity $X_{a}$ is determined from formula (8) [34]:

$$
X_{a}=0.622 \frac{p_{w}}{p_{a}-p_{w}}
$$

The partial pressure of water vapour $p_{w}$ for drying air $\left(X_{a}\right)$ is calculated as $(\varphi / 100) \cdot p_{w}^{\prime \prime}$, and for saturated air above the surface of the honey $\left(X_{a}^{\prime \prime}\left(T_{\tau}, A_{w}\right)\right)$ as $A_{w} \cdot p_{w}^{\prime \prime}$.

Knowing the initial parameters of the drying air $\left(T_{a-i n, \tau}, \varphi_{a-i n, \tau}\right)$ and honey $\left(T_{\tau}, X_{\tau}\right)$ and applying the correlations (1-2), and relationships (4-8), the honey temperature $T_{\tau+\delta \tau}$ at the next time step can be determined from Equation (3). The input air parameters at the beginning of each time period can be determined from the heat balance (9) and the balance (10) of the air moisture content for the cooling unit (Figure 1):

$$
\begin{gathered}
H_{a-o u t, \tau}+L=Q_{r}+H_{a-i n, \tau+\delta \tau} \equiv \dot{m}_{a} \cdot h_{a-o u t, \tau} \cdot \delta \tau+\dot{L} \cdot \delta \tau=\delta m \cdot r+\dot{m}_{a} \cdot h_{a-i n, \tau+\delta \tau} \cdot \delta \tau \\
X_{a-i n, \tau+\delta \tau}=\frac{m_{w, \tau}-\delta m}{m_{w, \tau}+m_{a}-\delta m} \equiv \frac{X_{a-o u t, \tau} \cdot \dot{m}_{a} \cdot \delta \tau-\delta m}{\left(1+X_{a-o u t, \tau}\right) \cdot \dot{m}_{a} \cdot \delta \tau-\delta m}
\end{gathered}
$$

The degree of humidity of the air $X_{a-i n, \tau+\delta \tau}$ Equation (10) and the value of the enthalpy of the inlet air $\left(h_{a-i n, \tau+\delta \tau}\right)$ determined from Equation (9) enable the calculation-using the formula for enthalpy of humid air (Equation (11)) —of the temperature of the air $T_{a-i n, \tau+\delta \tau}$ at the inlet to the dehydrator tank.

$$
h_{a-i n, \tau+\delta \tau}=c p_{a} \cdot T_{a-i n, \tau+\delta \tau}+X_{a-i n, \tau+\delta \tau} \cdot\left(r+c p^{\prime \prime} \cdot T_{a-i n, \tau+\delta \tau}\right)
$$

The amount of water condensed from the air on the evaporator surface of the cooling unit $\delta m$ is determined from Equation (12):

$$
\delta m=\operatorname{MIN}\left(\delta m_{H}, \delta m_{w}\right),
$$

in which the change in moisture content of air $\delta m_{w}$ follows the amount of latent heat $Q_{r}$ exchanged in the evaporator of the cooling unit $\left(\delta m_{w} \cdot r=Q_{r}\right)$.

Using Equations (9)-(11) to calculate the air temperature $T_{a-i n, \tau+\delta \tau}$ therefore requires knowledge of the enthalpy $\left(H_{a-o u t, \tau}\right)$ of the humid air leaving the dehydrator tank. The value of this enthalpy for the time $\tau$ can be determined from the heat balance Equation (13) of the dehumidifier tank, (Figure 1 balance shield marked in blue).

$$
H_{a-\text { in }, \tau}+\dot{Q}_{\text {heat }} \cdot \delta \tau=H_{a-o u t, \tau}+\dot{Q}_{L} \cdot \delta \tau+\delta Q_{\text {tank }}+\delta Q_{H}+\delta m_{H} \cdot h^{\prime \prime}\left(T_{\tau+\delta \tau}\right)
$$

In this case, the heat supplied by the heaters and the air is transferred to the honey $\left(\delta Q_{H}+\delta m_{H} \cdot h^{\prime \prime}\left(T_{\tau+\delta \tau}\right)\right)$, to the casing of the tank $\left(\delta Q_{\text {tank }}=m_{\text {tank }} \cdot c p_{\text {tank }}\left(T_{\tau+\delta \tau}-T_{\tau}\right)\right)$, the temperature of which increases with the temperature of the honey $\left(T_{H} \approx T_{\text {tank }}\right)$, and as heat losses to the environment $\left(\dot{Q}_{L}\right)$. The heat loss to the environment $\dot{Q}_{L}$ in Equation (13) refers to the total surface area of the tank.

Solving the system of balance Equations (3), (9), (10) and (13) enables the determination of the change over time in the temperature of honey and air, the change in the moisture content of honey, and the mass of water removed from the honey. The initial conditions $(\tau=0)$ which should be assumed to solve the system of Equations (3), (9), (10) and (13) are:

- Initial mass of honey in the tank, $m_{H}$;

- Initial temperature of honey and its moisture content, $T, X$;

- Initial temperature and relative humidity (of air), $T_{a}, \varphi_{a},\left(X_{a}\right)$;

- Ambient temperature, $T_{a m b}$.

The model also requires the determination of the air flow rate $\dot{V}_{a}$, tank weight, heater power $\dot{Q}_{\text {heat }}$, and operating specifications of the cooling unit. The considered model assumes that the cooling power $\left(\dot{Q}_{o}\right)$ and electricity consumption $(\dot{L})$ of the heat pump 
correspond to the parameters characteristic of the refrigeration compressor installed in the unit. The cooling unit of the dehydrator was equipped with an Embraco-Aspera NB5128Z refrigeration compressor ( $\mathrm{HBP}, \mathrm{ASHRAE}$ standard, $\left.T_{k}=54{ }^{\circ} \mathrm{C}\right)$, for which in the evaporation temperature range $(-5 ; 15){ }^{\circ} \mathrm{C}$, the operating characteristics were approximated by Equations (14) and (15).

$$
\begin{aligned}
& \dot{Q}_{o}=0.2325 \cdot T_{o}^{2}+14.99 \cdot T_{\mathrm{o}}+357.4 \\
& \dot{L}=-0.0558 \cdot T_{o}^{2}+2.175 \cdot T_{\mathrm{o}}+181.8
\end{aligned}
$$

The amount of latent heat exchanged in the evaporator of the cooling device was determined from the definition of the degree of openness of the air cooling process $R C$ J (degree of process openness) [35]:

$$
\dot{Q}_{r}=\dot{Q}_{o} \cdot \frac{R C J-1}{R C J}
$$

The value of RCJ coefficient Equation (17) was determined as a function of evaporation temperature $\left(T_{o}\right)$ and temperature of air at the evaporator inlet $\left(T_{a-o u t, \tau}\right)$ as well as degrees of humidity of air at the evaporator inlet $\left(X_{a-o u t, t}\right)$ and saturated air at the temperature of the external surface of the evaporator $\left(T_{w \text {-out }} \approx T_{o}\right)$

$$
R C J=1+\frac{r}{c p_{a}} \frac{\left(X_{a-o u t, \tau}-X_{a}^{\prime \prime}\left(T_{o}\right)\right)}{\left(T_{a-o u t, \tau}-T_{o}\right)}
$$

The RCJ coefficient is related to the directional coefficient of conversion $\varepsilon=\Delta h_{a} / \Delta X_{a}$ (read from the psychrometric chart of humid air) as follows $R C J=1 /\left(1-r \varepsilon^{-1}\right)$.

The calculation algorithm described by Equations (1)-(17) was used to prepare a spreadsheet in Excel and QBasic for the analysis of the heat and mass transfer process in the honey dehydrator over the time interval $(0, \tau)$ with the time step $d \tau$.

The system of Equations (1)-(17) was solved step by step. For known initial conditions of honey and air, assumed geometric parameters, and dehydrator operating conditions $(n$, $\left.\dot{V}_{a}, \dot{Q}_{\text {heat }}, m_{H}\right)$, the following values were determined:

- Values $h_{a-i n, \tau}, A_{w}, \beta, \delta m_{h}, \alpha$ respectively from Equations (1), (2), (6), (7) and (11);

- Honey temperature $(T \tau+\delta \tau)$ from Equations (3)-(5);

- $\quad$ Air enthalpy $\left(H_{a-o u t, \tau}\right)$ at the dehydrator outlet at time $\tau$ from Equation (13);

- $\quad R C J$ values, $\dot{Q}_{o}, \dot{Q}_{r}$, from Equations (14), (16) and (17), respectively;

- Actual mass of water $\delta m$ removed from honey from relationship (12) and relationship $\left(\delta m_{w} \cdot r=Q_{r}\right)$;

- The degree of humidity of the air $\left(X_{a-i n, \tau+\delta \tau}\right)$ returning to the dehydrator tank in time $\tau+\delta \tau$ from Equation (10);

- $\quad$ Specific air enthalpy $h_{a-i n, \tau+\delta \tau}$ from Equation (9);

- Temperature of the air $\left(T_{a-i n, \tau+\delta \tau}\right)$ returning to the dehydrator tank in time $\tau+\delta \tau$ from Equation (11).

Calculations were performed until either the expected moisture content of the honey or the assumed drying time was reached.

\section{Results and Discussion}

\subsection{Experimental Verification of the Numerical Model of the Honey Dehydrator}

Experimental verification of the honey dehydrator was performed based on the experimental results presented in [17] for the following dehydrator parameters:

- $\quad$ Mixer speeds: $n=120,165,270 \mathrm{rpm}$.

- $\quad$ Average air volume flow, its initial moisture content and initial temperature: $\dot{V}_{a}=0.01$; $0.016,0.024 \mathrm{~m}^{3} \mathrm{~s}^{-1}, 24 \%<\varphi h_{a, \tau=0}<36 \%, 20{ }^{\circ} \mathrm{C}<T h_{a, \tau=0}<36{ }^{\circ} \mathrm{C}$. 
- Mass of honey, its initial moisture content and initial temperature: $m_{H}=28 \mathrm{~kg}$, $X_{\tau=0} \approx 0.24,16.5^{\circ} \mathrm{C}<T h_{\tau=0}<24{ }^{\circ} \mathrm{C}$.

- Ambient temperature $16.5^{\circ} \mathrm{C}<T h_{a m b}<20^{\circ} \mathrm{C}$.

- The physical properties of honey were determined according to the relationships presented in articles [17,36-38] and for the air according to [39].

The heat pump used in the honey dehydrator is equipped with a thermostatic expansion valve (TXV). The variable thermal load of the heat-pump evaporator made the refrigerant evaporation temperature vary between 0 and $15^{\circ} \mathrm{C}$ during the honey dehumidification process. A constant evaporation temperature, corresponding to the mode of the evaporating temperature within its range, was used in numerical calculations. The most frequent temperatures were 10 or $15^{\circ} \mathrm{C}$.

A comparison of the calculation results and experimental results of the change in moisture content of dried honey for a fixed mixer speed $n=120 \mathrm{rpm}$ and different air flows are presented in Figure 2. Compared to paper [17], the measurement database used to verify the calculation model was expanded by tests for a rotational speed of $n=120 \mathrm{rpm}$ and an average air flow rate of $\dot{V}_{a}=0.016 \mathrm{~m}^{3} \mathrm{~s}^{-1}$. Figure 3 shows the validation of the calculation results for a fixed air flow rate $\dot{V}_{a}=0.024 \mathrm{~m}^{3} \mathrm{~s}^{-1}$ and different mixer speeds. Figure 4 shows a comparison of the calculated volume of water removed from honey. Figures $2-4$ indicate that the proposed model correctly qualitatively and quantitatively describes the dehydration process of honey in the dehydrator.

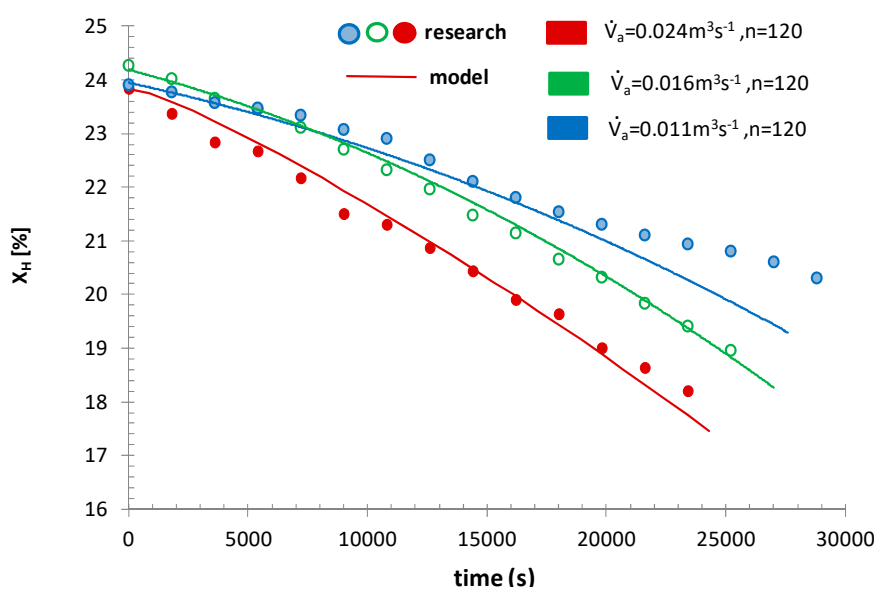

Figure 2. Comparison of the calculated and experimental values of honey moisture as a function of time $X_{H}(\tau)$, for $n=120 \mathrm{rpm}$.

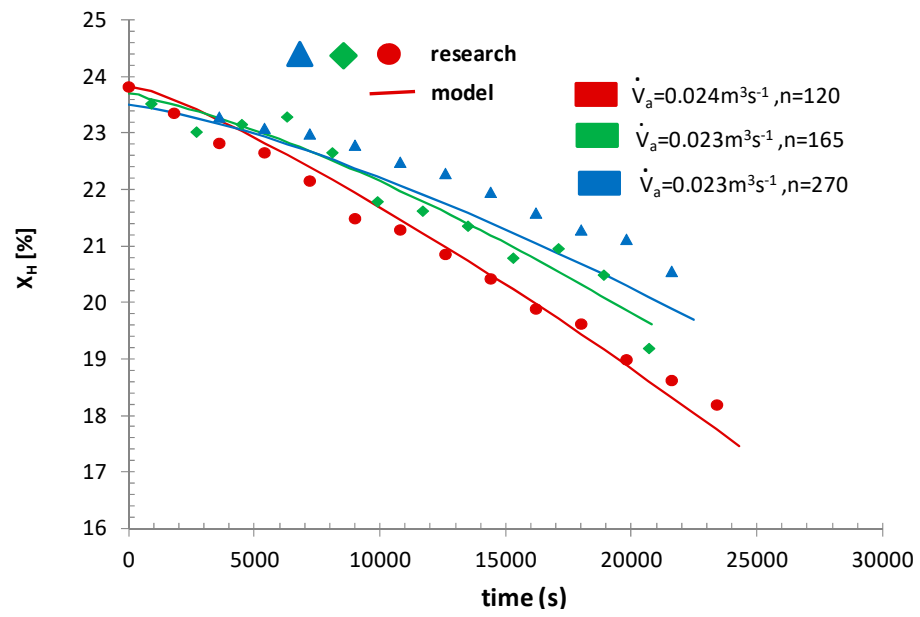

Figure 3. Comparison of the calculated and experimental values of honey moisture as a function of time $X_{H}(\tau)$, for $\dot{V}_{a} \approx 0.023-0.024 \mathrm{~m}^{3} \mathrm{~s}^{-1}$. 


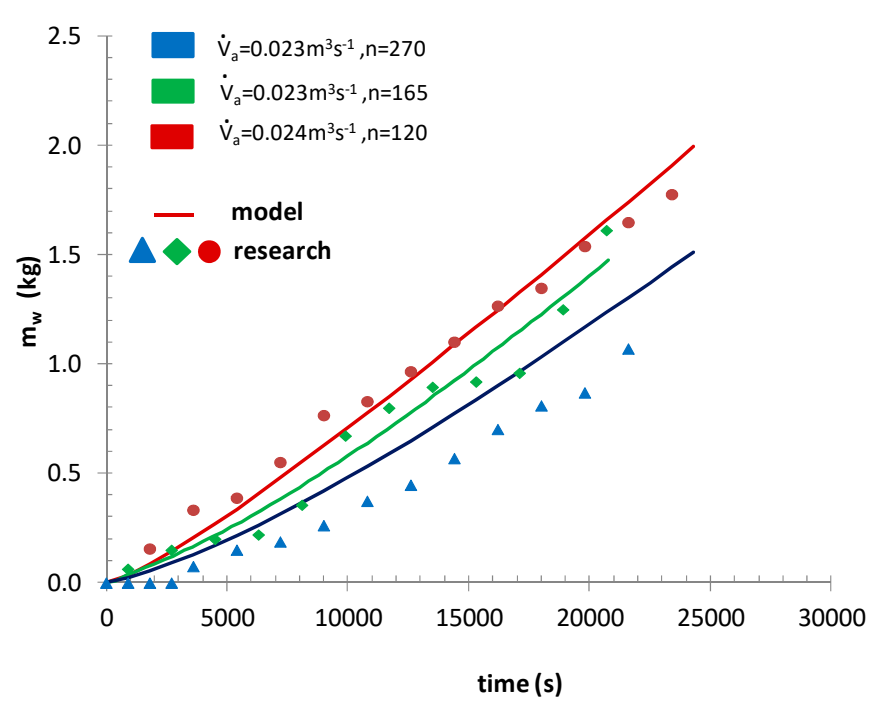

Figure 4. Comparison of the calculated and experimental values of the amount of water removed from honey as a function of time $m_{w}(\tau)$, for $\dot{V}_{a} \approx 0.023-0.024 \mathrm{~m}^{3} \mathrm{~s}^{-1}$.

Experimental research confirms that low mixer speeds corresponded to the maximum values of heat transfer and mass transfer coefficients. Hence, reducing the mixer speed by 2.25 times results in an absolute decrease in final honey moisture of approx. $2 \%$, and a reduction in drying time by a factor of 1.3-1.38. Additionally, higher air flow velocities and higher heat flux densities are conducive to higher values of heat transfer coefficients.

As result of a 2.24-fold increase in air flow rate, the final moisture content of honey is reduced by $3 \%$ and the drying time is reduced by 1.3-1.6, depending on the evaporation temperature. Table 2 summarises the agreement between the calculation and measurement results of honey moisture content. The average relative error of honey moisture determination for all cases is low and does not exceed $2 \%$. For the lowest airflow rate, the maximum error in calculating the instantaneous moisture value of honey relative to the measured results was $7.7 \%$. This discrepancy may be due to the low experimental and calculated values of heat and mass transfer coefficients, whose values may be subject to the largest measurement error [17].

Table 2. Accuracy of honey moisture determination for the adopted dehydrator calculation model.

\begin{tabular}{|c|c|c|c|c|c|}
\hline \multirow{2}{*}{ Calc. Variant } & \multicolumn{3}{|c|}{$n=120 \mathrm{rpm}$} & $\begin{array}{c}n= \\
165 \mathrm{rpm}\end{array}$ & $\begin{array}{c}n= \\
270 \mathrm{rpm},\end{array}$ \\
\hline & $\dot{V}_{a}=0.011 \mathrm{~m}^{3} \mathrm{~s}^{-1}$ & $\dot{V}_{a}=0.016 \mathrm{~m}^{3} \mathrm{~s}^{-1}$ & $\dot{V}_{a}=0.024 \mathrm{~m}^{3} \mathrm{~s}^{-1}$ & \multicolumn{2}{|c|}{$\dot{V}_{a}=0.023 \mathrm{~m}^{3} \mathrm{~s}^{-1}$} \\
\hline $\max . \operatorname{err}(\%)$ & 7.7 & 0.6 & 2.4 & 2.1 & 1.9 \\
\hline avg. err (\%) & 2 & 0.02 & 0.2 & 0.03 & 1.1 \\
\hline$\sigma_{X_{H}}$ & 0.36 & 0.10 & 0.25 & 0.30 & 0.26 \\
\hline$S_{X_{H}}$ & 0.46 & 0.013 & 0.062 & 0.084 & 0.24 \\
\hline
\end{tabular}

The final values of the amount of water removed away from the honey by air were calculated relative to the experimentally measured values. The relative discrepancy $\left(\frac{x_{c a l}-x_{\text {exp }}}{x_{\text {exp }}} \cdot 100 \%\right)$ of calculations and measurements was $7.3 ;-5.5 ;-10 \%$ for mixer speeds $n=120 ; 165 ; 270 \mathrm{rpm}$, respectively.

Comparison between calculated and experimentally obtained [17] distributions in time of honey temperature $\left(T_{H}\right)$ and drying air temperature $\left(T_{a-i n}\right)$ for the dehydrator parameters $n=120 \mathrm{rpm}, \dot{V}_{a}=0.024 \mathrm{~m}^{3} \mathrm{~s}^{-1}$ is presented in Figure 5. This confirms the nature of the temperature distributions obtained in the simulation and in the experiment. However, it should be noted that the calculated temperature distribution indicates faster 
stabilization of heat and mass transfer conditions. This may be due to the adopted model of a heat pump with constant evaporation temperature and differences in obtained values of heat and mass transfer coefficients. The mean relative difference between calculated and measured temperature was $5 \%$ for the honey and $2.2 \%$ for the air. The standard deviations of the sample for differences in calculated $\left(T_{\text {cal }}\right)$ and measured $\left(T_{\text {exp }}\right)$ values for honey and air temperatures are, respectively, $\sigma_{T_{H}}=0.74 ; \sigma_{T_{a}}=0.44$. The sums of squares of the differences of calculated and measured values for honey and air temperatures are, respectively, $S_{T_{H}}=3.47 ; S_{T_{a}}=0.93$. When validating the calculation model, the time step of $\delta \tau$ was adopted, corresponding to the time step in which the measurements were made $(\delta \tau=900 \mathrm{~s})$.

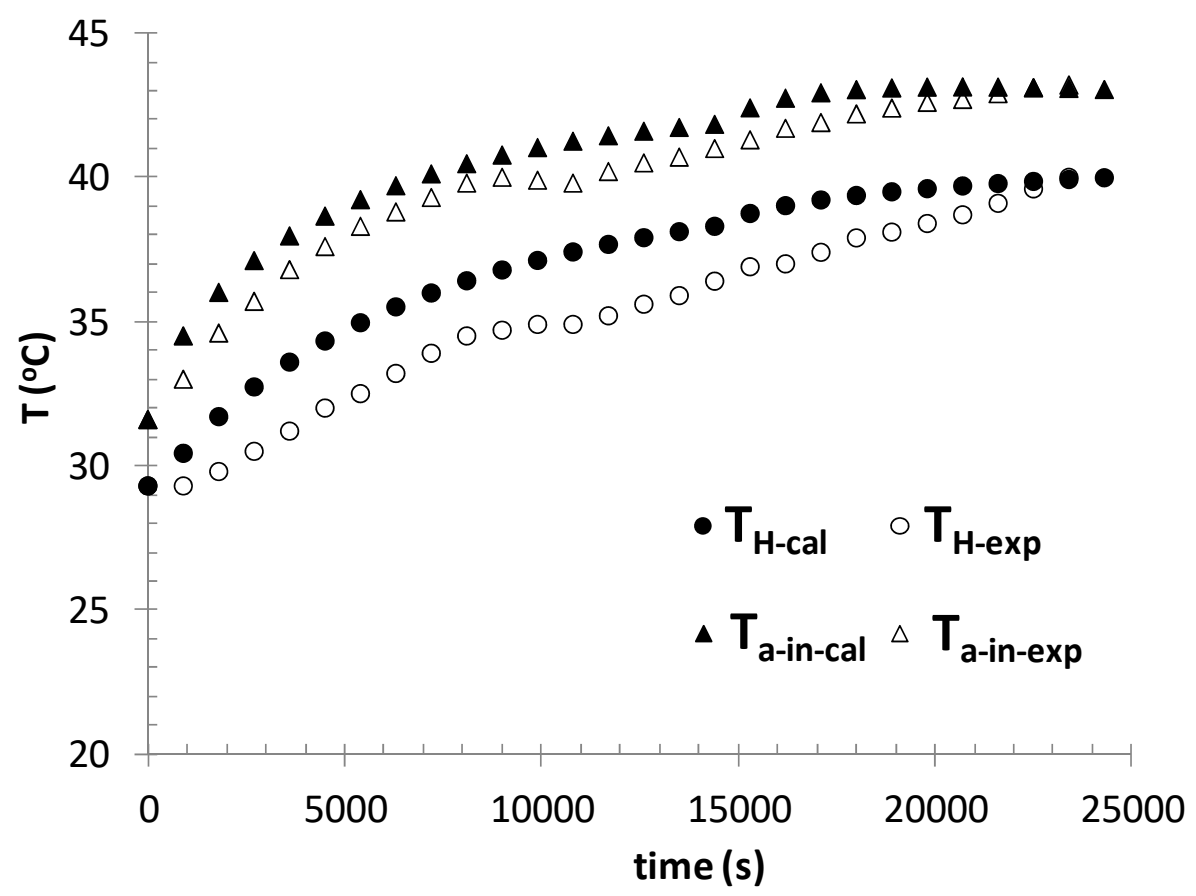

Figure 5. Comparison of the calculated and measured values of the temperature of honey and air, $n=$ $120 \mathrm{rpm}, \dot{V}_{a} \approx 0.024 \mathrm{~m}^{3} \mathrm{~s}^{-1}$.

The effect of the time step on the results of honey moisture calculations for different variants of calculations is presented in Table 3.

Table 3. Effect of the time step on honey moisture calculation results $\tau=24,300$.

\begin{tabular}{ccccc}
\hline Time Step $\delta \boldsymbol{\tau}$ (s) & $\mathbf{1 0 0}$ & $\mathbf{3 0 0}$ & $\mathbf{9 0 0}$ & $\mathbf{1 2 0 0}$ \\
\hline Calculation Variant & \multicolumn{3}{c}{$\boldsymbol{X}_{\boldsymbol{H}} \mathbf{( \% )}$} \\
\hline$n=120 \mathrm{rpm}, \dot{V}_{a}=0.024 \mathrm{~m}^{3} \mathrm{~s}^{-1}$ & 17.44 & 17.44 & 17.46 & 17.47 \\
$n=270 \mathrm{rpm}, \dot{V}_{a}=0.023 \mathrm{~m}^{3} \mathrm{~s}^{-1}$ & 19.22 & 19.24 & 19.29 & 19.39 \\
$n=120 \mathrm{rpm}, \dot{V}_{a}=0.016 \mathrm{~m}^{3} \mathrm{~s}^{-1}$ & 19.46 & 19.42 & 19.17 & 18.86 \\
\hline
\end{tabular}

The greatest differences in calculated honey moisture content values were obtained in the final phase of the drying. Table 3 shows that between the time steps $\delta \tau=100 \mathrm{~s}$ and $\delta \tau=900 \mathrm{~s}$, the discrepancies between the obtained calculation results do not exceed $1.4 \%$ (variant $n=120 \mathrm{rpm}, \dot{V}_{a}=0.016 \mathrm{~m}^{3} \mathrm{~s}^{-1}$ ). Therefore, adopting the time step $\delta \tau=900 \mathrm{~s}$ in the calculations for all variants of the calculations allows us to determine the moisture content of the dried honey with satisfactory accuracy. 


\subsection{Selection of Optimal Operating Parameters for the Cooling Unit}

The presented dehydrator calculation model can be used to determine the predicted honey drying time. The drying time is not only determined by the process of heat and mass exchange between the air and honey in the dehydrator tank, but also depends on the operation of the cooling unit in which the air is dehumidified and heated. Low evaporation temperatures promote intense condensation of moisture from the air. On the other hand, for higher evaporation temperatures, the cooling unit provides a higher heat capacity of the condenser where the air is heated. Thus, the dehydrator calculation model can be used to determine the optimal evaporation temperature of the cooling unit related to the minimum honey drying time. In the calculations, the cooling unit model shown by Equations (14)-(17) was assumed for a constant value of condensation temperature $\left(T_{k}=54{ }^{\circ} \mathrm{C}\right)$. The calculations were designed to minimise the drying time of the honey to commercial honey moisture values below $20 \%\left(X_{H}<20 \%\right)$. Calculations were performed for the measurement cases described in Section 3. The results of the calculations are presented in Figure 6.

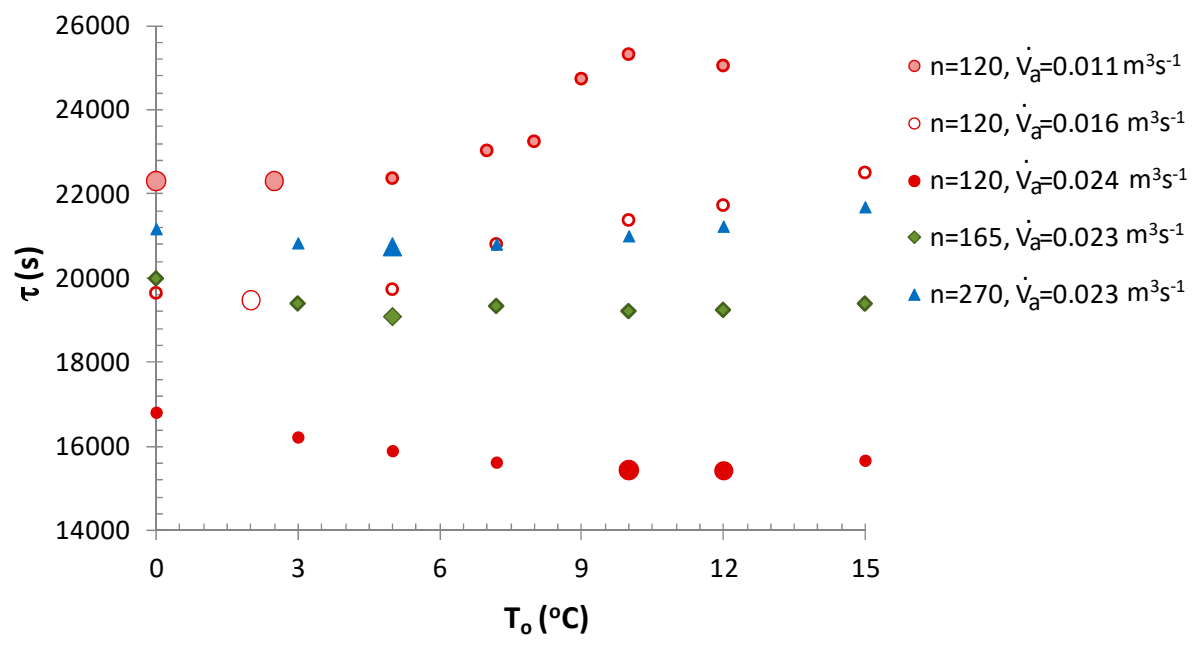

Figure 6. Drying time $\tau_{X_{H}<20 \%}\left(T_{o}\right)$ and optimum evaporation temperature values $T_{\mathrm{o}-\mathrm{opt}}$ corresponding to $\tau_{X_{H}<20 \%}=\tau_{\text {min }}$.

The calculation results presented in Figure 6 indicate that the honey drying time significantly depends on the intensity of the heat and mass transfer process in the dehydrator tank and thus on the dehydrator operating parameters: mixer speed and air volume flow rate. Reducing mixer speed by 2.25 times reduces drying time by a factor of $1.3-1.38$. In contrast, a 2.24-fold increase in volume flow reduces drying time by a factor of 1.3-1.6. The effect of changes in mixer speed, air volume flow rate on the reduction in drying time depends on the evaporation temperature $\left(T_{\mathrm{o}}\right)$ of the cooling unit.

After comparing the results of calculations for evaporation temperatures $T_{\mathrm{o}}=0{ }^{\circ} \mathrm{C}$ and $T_{\mathrm{o}}=12{ }^{\circ} \mathrm{C}$ (Figure 6), it can be noted that higher values of evaporation temperatures correspond to a greater reduction in drying time in the case of an increase in air volume flow and a reduction in the rotational speed of the mixers. A more significant effect of evaporation temperature on drying time is observed for low heat and mass transfer coefficients in the dehydrator tank. In the evaporation temperature range $0 \leq T_{\mathrm{o}} \leq 15^{\circ} \mathrm{C}$, the maximum change in drying time for conditions $n=120 \mathrm{rpm}, \dot{V}_{a}=0.011 \mathrm{~m}^{3} \mathrm{~s}^{-1}$ is $13 \%$, while for conditions $n=120 \mathrm{rpm}, \dot{V}_{a}=0.024 \mathrm{~m}^{3} \mathrm{~s}^{-1}-8 \%$. The enlarged markers in Figure 6 indicate the optimal evaporation temperature values of the cooling unit and the minimum time for the honey to reach a moisture content of $X_{H}<20 \%$. Analysis of the calculation results indicates that in the case of large values of the air flow rate (higher thermal load of the cooling device), it is advisable to use higher evaporation temperatures, which correspond to higher cooling capacities (case $n=120 \mathrm{rpm}, \dot{V}_{a}=0.024 \mathrm{~m}^{3} \mathrm{~s}^{-1}, T_{\mathrm{opt}}=10-12{ }^{\circ} \mathrm{C}$ ). In this 
case, large air flows receive large amounts of water with less driving force of the mass exchange process (smaller differences $\left.\Delta X=X^{\prime \prime}\left(T_{H}, A_{w}\right)-X\left(T_{a-i n}, \varphi_{a-i n}\right)\right)$. Since air is also the source of heat in the dehydrator tank, it is more important in this case to raise the air temperature in the condenser of the cooling unit. As the sensible and latent heat fluxes given off by the air in the cooling unit decrease, due to the poorer heat and mass transfer conditions in the dehydrator (e.g., the cases of $n=270 \mathrm{rpm}, \dot{V}_{a}=0.023 \mathrm{~m}^{3} \mathrm{~s}^{-1}, T_{\text {opt }}=5{ }^{\circ} \mathrm{C}$ and $n=120 \mathrm{rpm}, \dot{V}_{a}=0.011 \mathrm{~m}^{3} \mathrm{~s}^{-1}, T_{\text {opt }}=0-3{ }^{\circ} \mathrm{C}$ ), the optimal evaporation temperatures due to the drying time shift towards values lower than $5{ }^{\circ} \mathrm{C}$. Less favourable conditions of heat and especially mass exchange in the dehydrator are compensated in this case by the lower humidity of the air at the inlet to the dehydrator tank (outlet from the cooling device) and drying at a higher difference of partial pressures of water vapour in honey and air. Hence, lower evaporation temperatures associated with increased drying of the circulating air are optimal.

The SMER (specific moisture extraction) factor [15], which is the ratio of the mass of water withdrawn from the product and the amount of energy supplied to the drying unit, is often used to evaluate agricultural product dehumidifiers. In the case of the honey dehydrator under consideration, the driving energy of the device is related to the operation of the dryer heaters $\dot{Q}_{\text {heat }}$, the driving energy of the heat pump compressor $\dot{L}$ and the power of the fans pumping air through the unit. In the case under consideration, the amount of energy supplied to the drying unit was limited to the first two units ( $\dot{L}-$ Formula (15) $\dot{Q}_{\text {heat }}=195 \mathrm{~W}$ ) by determining the SMER coefficient from Formula (18)

$$
S M E R_{T_{o}}=\frac{m_{w}}{\left(\dot{L}_{T_{o}}+\dot{Q}_{\text {heat }}\right) \cdot \tau_{T_{o}}}
$$

Figure 7 shows the variation of $S M E R$ as a function of evaporation temperature and dehumidifier operating parameters.

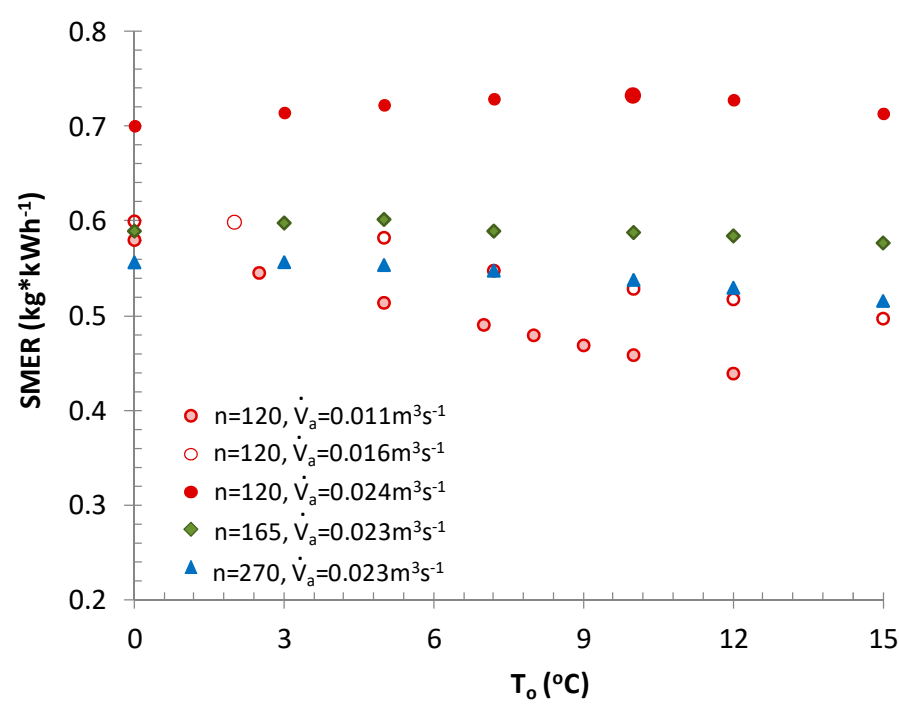

Figure 7. $S M E R$ coefficient dependence of dehydrator operating conditions, $\operatorname{SMER}\left(T_{0}, n, \dot{V}_{a}\right)$.

The maximum values of the $S M E R$ coefficient are shifted towards slightly lower evaporation temperatures due to the actual compressor characteristics. Analysis of the results shown in Figure 6 indicates that maximising the SMER value is associated with reducing the drying time. For fixed air flow rate values, the inclusion of fan power in Equation (18) also favours reducing the drying process time. 


\section{Conclusions}

This article presents a mathematical model of heat and mass transfer processes in a honey dehydrator with a heat pump and closed air circulation. The mathematical model of the dehydrator was verified experimentally in terms of the obtained moisture contents of the dried honey, the amount of water removed from the honey, and changes in air and honey temperature. The proposed calculation model both qualitatively and quantitatively correctly describes changes in honey moisture content over time with an average relative discrepancy of no more than $2 \%$. The mathematical model describing the processes occurring in the dehydrator was used to determine the optimal operating conditions of the cooling unit with which the dehydrator was equipped. The reduction in honey drying time below the moisture value of $20 \%$ indicates the dependence of the optimum evaporation temperature value on the flow rate of the circulating air and the speed of the dehydrator mixers. The optimum values of evaporation temperature, for the lowest values of heat and mass transfer coefficients in the dehydrator tank, corresponded to $T_{\mathrm{o}}=0-3{ }^{\circ} \mathrm{C}$, for $\dot{V}_{a}=0.011 \mathrm{~m}^{3} \mathrm{~s}^{-1}$ for mixer speed $n=120 \mathrm{rpm}$. For moderate heat and mass transfer conditions in the dehydrator tank, the optimal evaporation temperature value of the cooling unit was $T_{o} \approx 5{ }^{\circ} \mathrm{C}$ for $\dot{V}_{a}=0.023 \mathrm{~m}^{3} \mathrm{~s}^{-1}, n=165-270 \mathrm{rpm}$. For large heat fluxes exchanged by air in the dehydrator tank, the optimum evaporation temperature range was $T_{o} \approx 10-12{ }^{\circ} \mathrm{C}$. For fixed mixer speed and air flow rates, optimal values of evaporation temperatures allow for an $8-13 \%$ reduction in honey drying time. However, proper selection of the rotational speed of mixers and the air flow rate, as well as the evaporation temperature of the cooling unit, can reduce the honey drying time by up to $64 \%$.

The presented mathematical model of the dehydrator can be used to design honey dehydrators, meeting the geometric and hydraulic similarity conditions and to appropriately select the cooling unit of the dehydrator. The mathematical model enables the prediction of the drying time and can also be used to select optimal dehydrator operating parameters, mixer speed, air volume flows, and the evaporative temperature of the cooling unit.

The results of optimisation calculations also indicate that for honey dehydrators, it is advisable to use the elements of supply of the evaporators of cooling unit controlled as a function of evaporation pressure, which can be individually adjusted for air volume flow rate and mixer speed.

\section{Patents}

Malec M., Morawski M., 2019, Vertical, centrifugal, honey dehydrator, patent application no. P.430912.

Author Contributions: Methodology, formal analysis, writing-original draft preparation, data curation B.N.-Ż.; software, validation, visualization M.M. (Marcin Morawski); conceptualization, review and editing M.M. (Marcin Malec). All authors have read and agreed to the published version of the manuscript.

Funding: This research received no external funding.

Institutional Review Board Statement: Not Applicable.

Informed Consent Statement: Not Applicable.

Data Availability Statement: The data presented in this study are available on request from the corresponding author. The data are not publicly available due to being the private property of authors Marcin Malec and Marcin Morawski.

Acknowledgments: Administrative support of Mechanical Faculty of Cracow University of Technology.

Conflicts of Interest: The authors declare no conflict of interest. 


\section{Abbreviations}

A surface area $\left(\mathrm{m}^{2}\right)$

$A_{w} \quad$ water activity of honey, (-)

$B_{i} \quad$ coefficient in Equation (1), (-)

$C_{i} \quad$ coefficient in Equation (2), (-)

cp specific heat, $\left(\mathrm{Jkg}^{-1} \mathrm{~K}^{-1}\right)$

$d_{H} \quad$ hydraulic diameter, $\mathrm{d}_{\mathrm{h}}=4 \mathrm{~V} / \mathrm{A}_{\mathrm{V}},(\mathrm{m})$,

$d_{m} \quad$ diameter of mixer, $(\mathrm{m})$

$D \quad$ water vapor diffusion coefficient in air, $\left(\mathrm{m}^{2} \mathrm{~s}^{-1}\right)$

$h \quad$ specific enthalpy, $\left(\mathrm{Jkg}^{-1}\right)$

$h^{\prime \prime} \quad$ specific enthalpy of water vapour at the temperature $\mathrm{T},\left(\mathrm{Jkg}^{-1}\right)$

$H \quad$ entalpy, (J)

HBP hight pressure compressors

$\mathbf{K} \quad$ phase transition number, $\mathbf{K}=\frac{\Delta h_{v}}{\left(T_{a-i n}-T_{H}\right) \cdot c p_{a}},(-)$

$\dot{L} \quad$ compressor power input, $(\mathrm{W})$

$m$ mass, $(\mathrm{kg})$

$\dot{m}_{a} \quad$ dry air mass flow rate, $(\mathrm{kg})$

$n \quad$ rotational speed of the mixer $(\mathrm{rpm})$

$\mathrm{Nu} \quad$ Nusselt number, $\frac{\alpha \cdot d_{h}}{\lambda_{a}}$

$p_{a} \quad$ atmospheric pressure, $(\mathrm{Pa})$

$p_{w} \quad$ partial pressure of water vapour, $(\mathrm{Pa})$

$p^{\prime \prime} \quad$ water vapour pressure in air at the state of saturation, (Pa)

$\mathrm{Pr} \quad r$ - heat of water evaporation at $0{ }^{\circ} \mathrm{C},\left(\mathrm{Jkg}^{-1}\right)$ Prandtl number

$\boldsymbol{R} \boldsymbol{e}_{a} \quad$ air Reynolds number, $\boldsymbol{R} \boldsymbol{e}_{\boldsymbol{a}}=\frac{\boldsymbol{u}_{a} \cdot \boldsymbol{d}_{h} \cdot \boldsymbol{\rho}_{a}}{\mu_{a}}$

$\boldsymbol{R} \boldsymbol{e}_{\boldsymbol{H}} \quad$ honey Reynolds number, $\boldsymbol{R}_{\boldsymbol{H}}=\frac{\boldsymbol{n} \cdot \boldsymbol{d}_{\boldsymbol{m}} \cdot \boldsymbol{\rho}_{H}}{\mathbf{4} \boldsymbol{\mu}_{H}}$

RCJ degree of process openness, (-)

$Q \quad$ amount of heat, (J)

$\dot{Q} \quad$ heat flow, (W)

$\dot{Q}_{r} \quad$ latent heat flux exchanged in the evaporator of the cooling unit, (W)

$u_{a} \quad$ air flow velocity, $\left(\mathrm{ms}^{-1}\right), \boldsymbol{u}_{\boldsymbol{a}}=\frac{\dot{\boldsymbol{V}}_{\mathrm{a}}}{A_{c s}}$

$S$ sum of squared differences between calculated and measured values,

$S=\frac{1}{N} \sum_{i=1}^{N}\left(x_{c a l}-x_{\text {exp }}\right)^{2}$

Sc Schmidt number $S c=\frac{\mu_{a} \cdot \Delta X \cdot 10^{3}}{D_{a} \cdot \rho_{a}}$

Sh Sherwood number, $\frac{\beta \cdot d_{h}}{D_{a} \cdot \rho_{a}}$

SMER specific moisture extraction, $\left(\mathrm{kg} \mathrm{kWh}^{-1}\right)$

$U \quad$ overall heat transfer coefficient, $\left(\mathrm{Wm}^{-2} \mathrm{~K}^{-1}\right)$

$V \quad$ volume occupied by air in the dehydrator tank, $\mathrm{m}^{3}$

$\dot{V} \quad$ flow rate, $\left(\mathrm{m}^{3} \mathrm{~s}^{-1}\right)$

$T$ temperature, $\left({ }^{\circ} \mathrm{C}\right)$

$T_{\tau} \quad$ temperature of honey in time $\tau,\left({ }^{\circ} \mathrm{C}\right)$

TXV type of thermostatic expansion valve

$X \quad$ absolute humidity in air, $\left(\mathrm{kgkg}^{-1}\right)$

$X^{\prime \prime} \quad$ absolute humidity in air at the state of saturation, $\left(\mathrm{kgkg}^{-1}\right)$

$X_{H} \quad$ mass fraction of water in honey $100 \%$, (\%)

$X_{\tau} \quad$ mass fraction of water in honey in time, $\left(\mathrm{kgkg}^{-1}\right)$

$\Delta X \quad$ difference in the absolute humidity, $\Delta X=X^{\prime \prime}\left(T_{\tau}, A_{w}\right)-X\left(T_{a-i n}, \varphi_{a-i n}\right),\left(\mathrm{kgkg}^{-1}\right)$ 


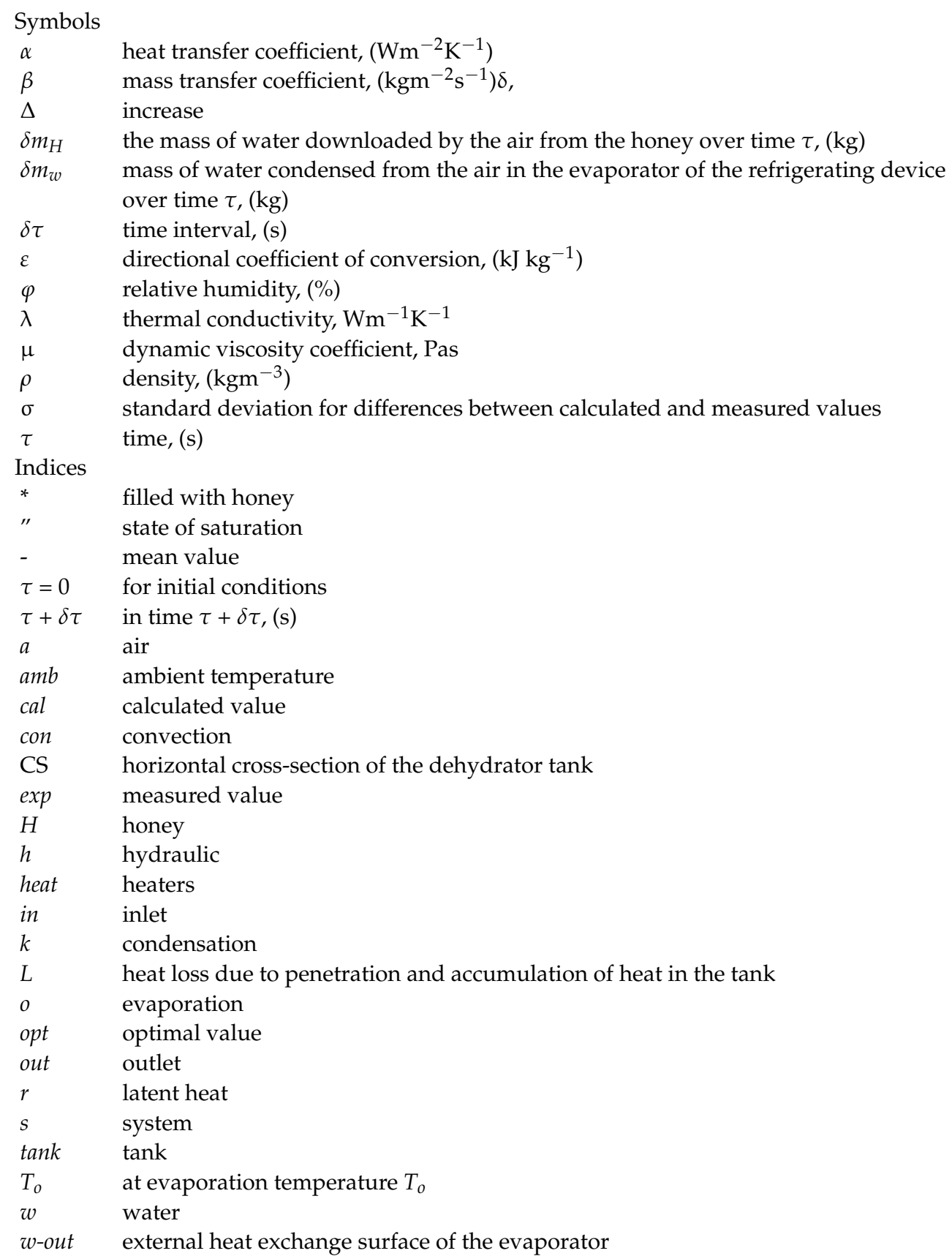

\section{References}

1. Umesh Hebbar, H.; Rastogi, N.K.; Subramanian, R. Properties of Dried and Intermediate Moisture Honey Products: A Review. Int. J. Food Prop. 2008, 11, 804-819. [CrossRef]

2. Singh, I.; Singh, S. Honey moisture reduction and its quality. J. Food Sci. Tecnol. 2018, 55, 3861-3971. [CrossRef] [PubMed]

3. Zlatanović, I. Types, Classification and Selection of Dryers in Agro Industry. Sci. J. Agric. Eng. 2012, 37, 1-13.

4. Platt, J.L., Jr.; Ellis, J.R.B. Removing Water from Honey at Ambient Pressure. U.S. Patent No. 4472450, 18 September 1984.

5. Wakhle, D.M.; Nair, S.K.; Phadke, R. Reduction of excess moisture in honey-I, a small scale unit. Indian Bee J. 1988, 50, 98-100.

6. Kuehl, L.J. Apparatus for Removing Moisture from Honey. U.S. Patent No. 4763572, 16 August 1988.

7. Ellis, M. Lowering the moisture content of small lots of extracted honey. Am. Bee J. 1987, 127, 182-183.

8. Maxwell, H. A small-scale honey drying system. Am. Bee J. 1987, 127, 284-286.

9. Singh, S.; Gill, R.S.; Singh, P.P. Desiccant honey dehydrator. Int. J. Ambient Energy 2011, 32, 62-69. [CrossRef]

10. Gill, R.S.; Hans, V.S.; Singh, S.; Singh, P.P.; Dhaliwal, S.S. A small scale honey dehydrator. J. Food. Sci. Technol. 2015, 52, 6695-6702. [CrossRef]

11. Chaudhary, O.P.; Wakhle, D.M. Honey processing plant with moisture reduction unit. J. Insect Sci. 1999, 12, 46-50. 
12. Wang, W.; Wu, L.; Li, Z.; Fang, Y.; Ding, J.; Xiao, J. An Overview of Adsorbents in the Rotary Desiccant Dehumidifier for Air Dehumidification. Dry. Technol. 2013, 31, 1334-1345. [CrossRef]

13. Ramli, A.S.; Basrawi, F.; Ibrahim, T.K.; Bin Yusof, M.H.; Oumer, A.N.; Johari, N.A.; Muhamad, A.; Mamat, M.R.; Habib, K Experimental analysis on a novel low-temperature vacuum drying with induced nucleation technique for dewatering stingless bees honey. Dry. Technol. 2018, 37, 149-155. [CrossRef]

14. Nedić, N.M.; Gojak, M.D.; Zlatanović, I.J.; Rudonja, N.R.; Lazarević, K.B.; Dražić, M.S.; Gligorević, K.B.; Pajić, M.B. Study of Vacuum and Freeze Drying of Bee Honey. Therm. Sci. 2020, 24, 4241-4251. [CrossRef]

15. Patel, K.K.; Kar, A. Heat pump assisted drying of agricultural produce-An overview. J. Food Sci. Technol. 2012, 49, 142-160. [CrossRef]

16. Subramanian, R.; Umesh Hebbar, H.; Rastogi, N.K. Processing of Honey: A Review. Int. J. Food Prop. 2007, 10, 127-143. [CrossRef]

17. Malec, M.; Morawski, M.; Niezgoda-Żelasko, B. Heat and mass transfer in a honey dehydrator with closed air circulation. Food Bioprod. Process. 2021, 125, 113-125. [CrossRef]

18. Halasz, B.A. General mathematical model of evaporative cooling devices. Rev. Gen. Therm. 1998, 37, 245-255. [CrossRef]

19. Camargo, J.R.; Ebinuma, C.D.; Cardoso, S. A mathematical model for direct evaporative cooling air conditioning system. Rev. Eng. Térmica 2003, 4, 30-34. [CrossRef]

20. Dhamneya, A.K.; Rajput, S.P.S.; Singh, A. Thermodynamic performance analysis of direct evaporative cooling system for increased heat and mass transfer area. Ain Shams Eng. J. 2018, 9, 2951-2960. [CrossRef]

21. Zalewski, W.; Niezgoda-Żelasko, B.; Litwin, M. Optimization of evaporative fluid coolers. Int. J. Refrig. 2000, 23, 553-565. [CrossRef]

22. Camargo, J.R.; Ebinuma, C.D. A mathematical model for direct and indirect evaporative cooling air conditioning systems. In Proceedings of the 9th Brazilian Congress of Thermal Engineering and Sciences, Caxambu, Brazil, 15-18 October 2002. [CrossRef]

23. Haghi, A.K. A Mathematical Model of the Drying Process. Acta Polytech. 2001, 41, 20-23. [CrossRef]

24. Adapa, P.K.; Schoenau, G.J.; Sokhansanj, S. Performance study of a heat pump dryer system for specialty crops, Part 1: Development of a simulation model. Int. J. Energy Res. 2002, 26, 1001-1019. [CrossRef]

25. Adapa, P.K.; Schoenau, G.J.; Sokhansanj, S. Performance study of a heat pump dryer system for specialty crops, Part 2: Model verification. Int. J. Energy Res. 2002, 26, 1021-1033. [CrossRef]

26. Teeboonma, U.; Tiansuwan, J.; Soponronnarit, S. Optimization of heat pump fruit dryers. J. Food Eng. 2003, 59, 369-377. [CrossRef]

27. Louarn, S.; Ploteau, J.P.; Glouannec, P.; Noel, H. Experimental and Numerical Study of Flat Plate Sludge Drying at Low Temperature by Convection and Direct Conduction. Dry. Technol. 2014, 32, 1664-1674. [CrossRef]

28. Hossain, M.A.; Gottschalk, K.; Hassan, M.S. Mathematical model for a heat pump dryer for aromatic plant. Procedia Eng. 2013, 56, 510-520. [CrossRef]

29. Hamid, M.; Usman, M.; Zubair, T.; Haq, R.U.; Wang, W. Shape effects of $\mathrm{MoS}_{2}$ nanoparticles on rotating flow of nanofluid along a stretching surface with variable thermal conductivity: A Galerkin approach. Int. J. Heat Mass Transf. 2018, 124, 706-714. [CrossRef]

30. Hamid, M.; Khan, Z.H.; Khan, W.A.; Haq, R.U. Natural convection of water-based carbon nanotubes in a partially heated rectangular fin-shaped cavity with an inner cylindrical obstacle. Phys. Fluids 2019, 31, 103607. [CrossRef]

31. Khan, Z.H.; Khan, W.A.; Hamid, M.; Liu, H. Finite element analysis of hybrid nanofluid flow and heat transfer in a split lid-driven square cavity with Y-shaped obstacle. Phys. Fluids 2020, 32, 093609. [CrossRef]

32. Malec, M.; Morawski, M. Vertical, Centrifugal, Honey Dehydrator. PL. Patent No. Pat. 239466, 8 September 2021.

33. Chen, C.H. Relationship between Water Activity and Moisture Content in Floral Honey. Foods 2019, 8, 30. [CrossRef] [PubMed]

34. Recknagel, H.; Sprenger, E.; Hönmann, W.; Schramek, E.R. Ogrzewanie, Klimatyzacja-Poradnik (Heating, Air Conditioning-Guide); EWFE: Gdańsk, Poland, 1994.

35. Niezgoda-Żelasko, B.; Żelasko, J. Free and forced convection on the outer surface of vertical longitudinally finned tubes. Exp. Therm. Fluid Sci. 2014, 57, 145-156. [CrossRef]

36. Niesteruk, R. Rozprawy Naukowe (62). In Właściwości Termofizyczne Żywności, Część II (Thermo-Physical Properties of Food, Part II); Politechnika Białostocka: Białytsok, Poland, 1999.

37. Mehryar, L.; Esmaiili, M.; Hassanzadeh, A. Evaluation of Some Physicochemical and Rheological Properties of Iranian Honeys and the Effect of Temperature on its Viscosity. Am. Eurasian J. Agric. Environ. Sci. 2013, 13, 807-819. [CrossRef]

38. Yanniotis, S.; Skaltsi, S.; Karaburnioti, S. Effect of moisture content on the viscosity of honey at different temperatures. J. Food Eng. 2006, 72, 372-377. [CrossRef]

39. Properties of Dry Air. VDI Heat Atlas; VDI Verlag: Düsseldorf, Germany, 2010. [CrossRef] 